\title{
The Impact of the CEDD-NET on the Evaluation of Rare Disorders: A Multicenter Scientific Research Platform in the Field of Pediatric Endocrinology
}

\author{
(D) Samim Özen1, (D) Aysun Ata22, (D) Feyza Darendeliler³ \\ ${ }^{1}$ Ege University Faculty of Medicine, Department of Pediatric Endocrinology, Izmir, Turkey \\ 2University of Health Sciences Turkey, Adana City Training and Research Hospital, Clinic of Pediatric Endocrinology, Adana, Turkey \\ 3istanbul University, Istanbul Faculty of Medicine, Department of Pediatric Endocrinology, Istanbul, Turkey
}

\section{What is already known on this topic?}

It is known that in some rare and special diseases, studies cannot be performed due to the insufficient number of patients, and thus experiences are published only in the form of case reports.

\section{What this study adds?}

We present pediatric endocrinologists with an example of a platform where they can produce large studies with low cost and a high number of patients.

\begin{abstract}
Objective: The database http://cedd.saglik-network.org (CEDD-NET) has been operating since 2013 in Turkey. All pediatric endocrinologists can propose projects to this network. The aim of our study was to determine the impact of CEDD-NET on the transformation of multicenter studies into scientific publications and assess the academic characteristics of the studies that have been transcribed into publication.

Methods: All the studies that were opened to patient admission on the website between August 26, 2013 and March 1, 2021 were reviewed.

Results: A total of 30 studies were accepted and opened for data entry. The median data collection period was 12 (1.5-24) months, while the median number of researchers participated was 23 (3-180), the median number of cases was 120 (26-192). The average cost was $\$ 2113$ (1370-3118). Out of 30 studies, data entry was completed for 27 . Sixteen publications were produced from 14 studies, 13 ot them have not published yet. The median time from the end of data entry to publication of the study was 686 (168-1608) days. While the median impact factor of the journals in which the studies were published was 1.803 (1.278-5.399), the median number of citations was 6.5 (0-49), and cited by 99 times in Web of Science indexed journals in total.

Conclusion: CEDD-NET appears to be productive and effective as all the publications are of high quality that have been published in the Q1-Q2 categories. This study demonstrated the benefits and necessity of establishing nationwide databases, even covering more than one country, in specialized branches, such as pediatric endocrinology where rare diseases are of concern.
\end{abstract}

Keywords: Nationwide studies, pediatric endocrinology, rare diseases, CEDD-NET

Address for Correspondence: Samim Ozen MD, Ege University Faculty of Medicine, Department of Pediatric Endocrinology, İzmir, Turkey

Phone: +902323901230 E-mail: samim.ozen@ege.edu.tr, samimozen@gmail.com

ORCID: orcid.org/0000-0001-7037-2713
Conflict of interest: None declared Received: 15.12.2021 Accepted: 07.01 .2022

${ }^{\circ}$ Copyright 2022 by Turkish Society for Pediatric Endocrinology and Diabetes

The Journal of Clinical Research in Pediatric Endocrinology published by Galenos Publishing House. 


\section{Introduction}

Pediatric endocrinology is a specialized discipline that deals with common endocrine disorders, such as obesity and hypothyroidism, in addition to several rare disorders. Disorders of sex development, hypophosphatemic rickets, hypoparathyroidism, and childhood thyroid cancers are among these rare diseases. The rarity of these diseases makes it almost impossible to conduct new studies from a single center, highlighting the need for large multicenter studies.

The Pediatric Endocrinology and Diabetes Society (PEDS) in Turkey is an association with a total of 357 members; that includes only pediatric endocrinologists. Thanks to the activities of this association, the database http://cedd.sagliknetwork.org (CEDD-NET) was established and has been operating since 2013. All pediatric endocrinologists can propose projects to this network. The project is evaluated by the members of the advisory board, consisting of 15 members who are the chairs of various Working Groups, in terms of ethical compliance and scientific content. Appropriate studies are finalized for data entry by the must approve of at least 8 out of 15 members of the advisory board. Software engineers create the data set and announce the project to all pediatric endocrinology and diabetes centers in the country via email. Those who want to participate in the research project, log-in to the website and report their intent. Later, the application is evaluated by the CEDD-NET coordinator. Centers whose participation is approved are then included in the study. The aim of this network is to conduct high quality, multicenter studies in the field of pediatric endocrinology, to investigate approaches and treatment responses in rare diseases, and to shed light on treatment approaches and guide future studies for physicians.

The aim of our study was to determine the impact of CEDD-NET on the transformation of multicenter studies into scientific publications and assess the academic characteristics of the studies that have been transcribed into publication.

\section{Methods}

In our study, all the studies that were opened to patient admission on the website http://cedd.saglik-network. org between August 26, 2013 and March 1, 2021 were reviewed. The number of participants in the studies, the number of cases, the number of parameters investigated, and the cost (at the dollar exchange rate on the date the study was opened for case recruitment) were documented. In the completed studies, the publication status of the study was investigated through Pubmed and Google Academic databases. The date of the publication, the impact factor of the published journal, the $\mathrm{Q}$ category, the number of citations by any publication, and by Web of Science journals were searched.

\section{Statistical Analysis}

Categorical data were described using observed frequencies and percentages, and continuous variables were summarized by their medians and minimum maximum values in case of serious deviation from normality with Statistical Package for the Social Sciences (SPSS), version 21.0 (SPSS Inc., Chicago, IL, USA). A p value $<0.05$ was considered to be statistically significant.

\section{Results}

A total of 30 studies were accepted and opened for data entry in the 7.5-year period from August 26, 2013, when the first study started, to March 1, 2021. While data entry was still ongoing in three of these studies, it had been closed in 27 studies and had been terminated. The median data collection period of the studies was 12 (1.5-24) months. While the median number of researchers who participated was 23 (3-180), the median number of cases was 120 (26192). The median number of investigated parameters was 154 (41-564). The average cost was $\$ 2113$ (1370-3118). Out of 30 studies, data entry was completed for 27 . Sixteen publications were produced from 14 studies, 13 of them were not yet published. From the data of one study, three different publications were produced (Table 1). The median time from the end of data entry to publication of the study was 686 (168-1608) days. While the median impact factor of the journals in which the studies were published was 1.803 (1.278-5.399), the median number of citations was 6.5 (0-49), and the median number of citations by Web of Science journals was 4 (0-22).

\section{Discussion}

The specialized field of endocrinology and metabolism is a field that deals with health problems, such as type 2 diabetes and obesity (1), which affects up to $30 \%$ of the population, as well as diseases with a frequency of $<1 / 1000000$ such as congenital lipodystrophy (2). Based on the bibliographic review of the studies conducted in the field of endocrinology and metabolism in the world, Turkey is in a good place (ranked $16^{\text {th }}$ ) among the countries producing the most publications (3). Thanks to the developments in the field of medicine, many new treatments are produced and the way for many new studies is paved. 


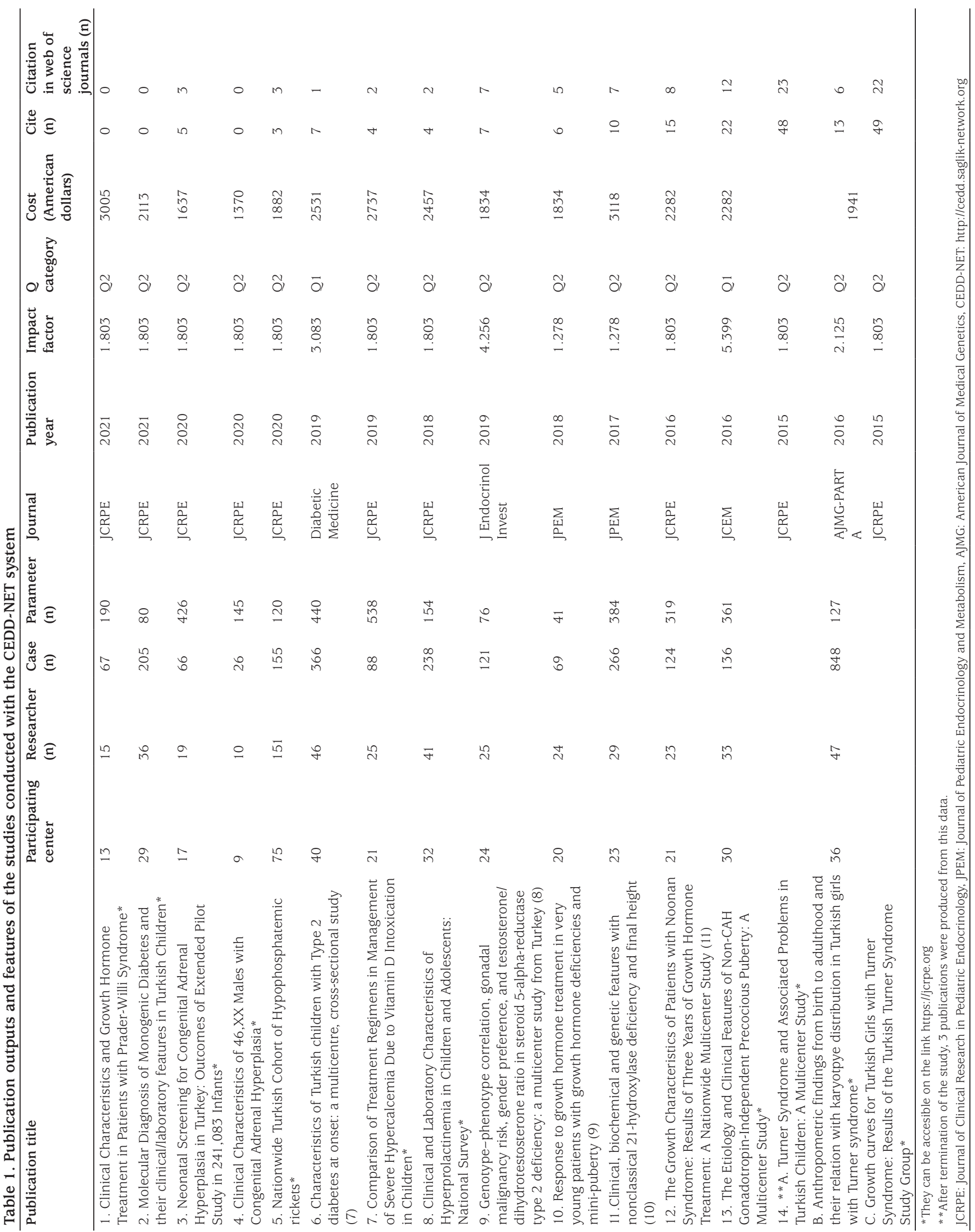


When citations of publications are examined, among the sub-fields of pediatrics, pediatric endocrinology is the third most cited field (4). Some endocrine disorders in this field are rare and do not allow clinical research from a single center (5). Examples of these diseases are PraderWilli syndrome, and 46 XX congenital adrenal hyperplasia reared as males. In addition, due to the insufficient number of cases followed by clinicians, their clinical experience is limited in these diseases (6). Through the data network established by PEDS, physicians both share their experiences with each other and get ideas about treatment approaches. When the publications of the PEDS are examined, the publication "Response to growth hormone treatment in very young patients with growth hormone deficiencies and mini-puberty" was reported as the largest series evaluating patients who were diagnosed with growth hormone deficiency and started treatment under the age of three years. Similarly, the publication "Genotype-phenotype correlation, gonadal malignancy risk, gender preference, and testosterone/dihydrotestosterone ratio in steroid 5-alpha-reductase type 2 deficiency: a multicenter study from Turkey", and "Clinical and laboratory characteristics of hyperprolactinemia in children and adolescents: national survey" are the studies with the largest patient series in their specific field. Likewise, the study "Comparison of treatment regimens in management of severe hypercalcemia due to vitamin D intoxication in children", which evaluated vitamin $\mathrm{D}$ intoxication, made a great contribution to the literature with the largest patient series in an area that is very difficult to study. All these papers can be accessible on the link https://jcrpe.org.

When the cost calculation of the studies was made, the highest amount was found to be $\$ 3,118$. Despite the fact that this amount was below the cost of many scientific research projects, publications of the high quality were produced. This suggests that studies with a data network can also be cost-effective.

One of the issues to be discussed is that only $51.8 \%$ of the studies have been published. The reasons that studies have not been published may include the low number of cases, insufficient data collection or difficulties experienced by corresponding authors to bring them to the publication stage. The fact that four publications have not been published, even though it has been more than 4 years since data entry was closed, reveals the necessity of reviewing researchers at the publication stage by the evaluation board.

\section{Study Limitations}

One of the limitations of the study is that the corresponding authors were not contacted individually. This would have allowed assessment of the negative and positive aspects of the data evaluation using the CEDD-NET system but we were unable to assess this. Furthermore, the problem of unpublished studies and if this was due to the data source, was also not investigated. The productivity and effectiveness of CEDD-NET would better have been assessed by canvassing the anonymous opinions of the researchers who provided data to the various studies.

\section{Conclusion}

In conclusion, the CEDD-NET database is cost-effective and useful, as it creates a data network that can easily reach many physicians across the country. It is productive and effective, as all the publications are of Q 1 -Q2 quality to date and have been cited by 99 Web of Science indexed journals in total. This study shows the benefits and necessity of establishing nationwide databases, even extending to more than one country, in specialized branches of medicine, such as pediatric endocrinology, where rare diseases are of concern and good quality evidence is scarce.

\section{Ethics}

Ethics Committee Approval and Informed Consent: Ethical approval and was not required for this research, as this study did not directly or indirectly involve human participants.

Peer-review: Externally peer-reviewed.

\section{Authorship Contributions}

Surgical and Medical Practices: Feyza Darendeliler, Concept: Aysun Ata, Feyza Darendeliler, Design: Samim Özen, Feyza Darendeliler, Data Collection or Processing: Aysun Ata, Analysis or Interpretation: Samim Özen, Literature Search: Samim Özen, Feyza Darendeliler, Writing: Samim Özen, Aysun Ata.

Financial Disclosure: The authors declared that this study received no financial support.

\section{References}

1. NCD Risk Factor Collaboration (NCD-RisC). Worldwide trends in body-mass index, underweight, overweight, and obesity from 1975 to 2016: a pooled analysis of 2416 population-based measurement studies in 128.9 million children, adolescents, and adults. Lancet 2017;390:2627-2642

2. Garg A. Acquired and Inherited Lipodystrophies. $N$ Engl J Med 2004;350:1220-1234

3. Zhao X, Ye R, Zhao L, Lin Y, Huang W, He X, Lian F, Tong X. Worldwide research productivity in the field of endocrinology and metabolism--a bibliometric analysis. Endokrynol Pol 2015;66:434-442. 
4. Chhapola V, Tiwari S, Deepthi B, Kanwal SK. Citation classics in pediatrics: a bibliometric analysis. World J Pediatr 2018;14:607-614. Epub 2018 Mar 6

5. López García MC, Moya Moya AJ, Sirvent Segovia AE, Ruiz de Assin Valverde A, García Blasco L, Quilez Toboso RP, Alfaro Martínez JJ. Analysis of the evolution of the publication of case reports in endocrinology journals [Análisis de la evolución en la publicación de casos clinicos en revistas de endocrinología]. Endocrinología, Diabetes y Nutrición 2022;69:189-193.

6. Massarrat S, Kolahdoozan S. Critical assessment of progress of medical sciences in Iran and Turkey: the way developing countries with limited resources should make effective contributions to the production of science. Arch Iran Med 2011;14:370-377.

7. Hatun S, Yesiltepe Mutlu G, Cinaz P, Turan S, Ekberzade A, Bereket A, Erbas MY, Akcay T, Onal H, Bolu S, Arslanoglu I, Doger E, Yilmaz AA, Ucakturk A, Karabulut GS, Tuhan HÜ, Demir K, Erdeve SS, Aycan Z, Nalbantoğlu Ö, Kara C, Gungor N; turkish type 2 diabetes research group. Characteristics of Turkish children with Type 2 diabetes at onset: a multicentre, cross-sectional study. Diabet Med 2019;36:12431250. Epub 2019 Jul 4

8. Abacı A, Çatlı G, Kırbıyık Ö, Şahin NM, Abalı ZY, Ünal E, Şıklar Z, Mengen E, Özen S, Güran T, Kara C, Yıldız M, Eren E, Nalbantoğlu Ö,
Güven A, Çayır A, Akbaş ED, Kor Y, Çürek Y, Aycan Z, Baş F, Darcan Ş, Berberoğlu M. Genotype-phenotype correlation, gonadal malignancy risk, gender preference, and testosterone/dihydrotestosterone ratio in steroid 5-alpha-reductase type 2 deficiency: a multicenter study from Turkey. J Endocrinol Invest 2019;42:453-470. Epub 2018 Aug 21

9. Çetinkaya S, Poyrazoğlu Ş, Baş F, Ercan O, Yıldız M, Adal E, Bereket A, Abalı S, Aycan Z, Erdeve ŞS, Berberoğlu M, Şıklar Z, Tayfun M, Darcan Ş, Mengen E, Bircan İ, Jones FMÇ, Şimşek E, Papatya ED, Özbek MN, Bolu $\mathrm{S}$, Abac1 A, Büyükinan $\mathrm{M}$, Darendeliler F. Response to growth hormone treatment in very young patients with growth hormone deficiencies and mini-puberty. J Pediatr Endocrinol Metab 2018;31:175-184.

10. Savaş-Erdeve Ş, Çetinkaya S, Abalı ZY, Poyrazoğlu Ş, Baş F, Berberoğlu M, Sıklar Z, Korkmaz Ö, Buluş D, Akbaş ED, Güran T, Böber E, Akın O, Yllmaz GC, Aycan Z. Clinical, biochemical and genetic features with nonclassical 21-hydroxylase deficiency and final height. J Pediatr Endocrinol Metab 2017,30:759-766.

11. Atay Z, Yesilkaya E, Erdeve SS, Turan S, Akin L, Eren E, Doger E, Aycan Z, Abali ZY, Akinci A, Siklar Z, Ozen S, Kara C, Tayfun M, Sari E, Tutunculer F, Karabulut GS, Karaguzel G, Cetinkaya S, Saglam H, Bideci A, Kurtoglu S, Guran T, Bereket A. The Etiology and Clinical Features of Non-CAH Gonadotropin-Independent Precocious Puberty: A Multicenter Study. J Clin Endocrinol Metab 2016;101:1980-1988. Epub 2016 Mar 10 